\title{
Excess weight and dyslipidemia and their complications during pregnancy: a systematic review
}

\author{
Iramar Baptistella do Nascimento 1 \\ Willian Barbosa Sales 2 \\ Raquel Fleig 3 \\ Grazielle Dutra da Silva 4 \\ Jean Carl Silva 5
}

\footnotetext{
1,2 Programa de Pós-graduação em Saúde e Meio Ambiente. Universidade da Região de Joinville (UNIVILLE). Joinville, SC, Brasil.

3 Centro de Educação do Planalto Norte. Universidade do Estado de Santa Catarina (CEPLAN/UDESC). Rua Luiz Fernando Hastreiter, 180. Centenário. São Bento do Sul, SC, Brasil. CEP: 89.283-081. E-mail: raquel.fleig@udesc.br

4,5 Universidade da Região de Joinville (UNIVILLE). Joinville, SC, Brasil.
}

\begin{abstract}
Objectives: to identify bibliographically disorders related to excess weight, dyslipidemia and their complication during pregnancy and in the fetus and newborn.

Methods: a systematic review including observational and interventional studies and reviews, based on MEDLINE, LILACS, Embase and the Cochrane Library between 2000 and 2015. The key-words "lipids, pregnancy, obesity and newborn" were used to establish a selective stage for inclusion/exclusion of titles, repeated studies, key-words, abstracts, methodological incompatibility and correlation with objectives.

Results: 58 studies were selected, of which $36(62 \%)$ addressed prevention and the risk in pregnancy of excess weight and lipid disorders and 19 (32.7\%) suggestions and/or consequences for the fetus and newborn.

Conclusions: excess weight and lipidemic disorders in pregnancy are causes for concern in scientific studies, posing risks both for the mother and the newborn. Higher prevalence of caesarian and pre-eclampsia were the two most noteworthy complications for gestational outcomes. In short, the impact on care of maternal habits and excess weight during pregnancy is highly significant, owing to the different degrees of complication in obstetric outcomes and their influence on the clinical characteristics of the newborn.
\end{abstract}

Key words Lipids, Pregnancy, Obesity, Infant, newborn 


\section{Introduction}

Dyslipidemia is characterized by abnormal levels of cholesterol and triglycerides. Generally speaking, the disorders caused by dyslipidemia gradually increase indices of overweight and is the principle cause of the nutritional disequilibrium that affects contemporary human beings and future generations, who will tend to face serious health problems in the long term. ${ }^{1}$ According to the World Health Organization (WHO), there are expected to be 700 million obese individuals in 2016, compared to an estimated 400 million in 2005.1

Under the conditions inherent to pregnancy, excess weight is a worrying disorder, especially when the woman has been obese or overweight since the first trimester, increasing the possibility of an adverse outcome. ${ }^{2}$ Hence, the high prevalence and lack of control of overweight and obesity prior to pregnancy require that more efficient procedures for managing weight gain be adopted in Brazil. ${ }^{3}$ Studies reveal that these problems are addressed in between $25 \%$ and $30 \%$ of pregnant women in the country. 3,4

The risks of obesity are various and include heightened cholesterolemia or trigliceridemia in isolation and mixed hyperlipidemic disorders. 5 Studies have shown2,6,7 that excessive weight gain in pregnancy poses greater risks both for the mother and the newborn. Gestational diabetes mellitus, preeclampsia and a higher frequency of caesarians may occur in the pregnant women, while the newborns are at risk of macrosomia and a greater likelihood of hospitalization in special care units. ${ }^{2}$

It is clear that obesity in pregnancy has become a common problem in pregnant women around the world. Since the early 1990s there has been growing concern among researchers and health professionals regarding excess weight during pregnancy. $2,3,5$ It is thus now of fundamental importance that researchers turn their attention to the specificities and peculiarities of gestational disorders, conditions which are not so normal in clinical terms and much less normal from a physiological point of view. 8

Thus, apart from issues of overweight and obesity, it is worth also noting the relations between risks and results observed, as in the study by Dempsey et al.,9 which included suggestions regarding the identification of factors associated with growth in the uterus. This may help prevent possible risks subsequent to alterations to lipid metabolism during pregnancy, which may be related to the occurrence of preeclampsia.

Although various factors may play a part in dyslipidemia and gestational weight gain, few studies have quantified and clarified these alte- rations. The present study thus aims to evaluate, based on scientific publications between 2000 and 2015, obesity and maternal dyslipidemia and complications during pregnancy in the fetus and the newborn.

\section{Methods}

The study focuses on pregnant women and obstetric outcomes between 2000 and 2015. A systematic search of the published bibliography was carried out in the MEDLINE, LILACS, Embase and Cochrane Library databases.

The selected key-words were "lipidic, pregnancy, obesity and newborn", combined with the Boolean operators "AND" and "OR" in such a way as to obtain articles relevant to the theme. 2909 articles were found.

The inclusion criteria for the articles evaluated in this study were applied as follows:

Scope of the study: a systematic review of clinical trials, cross-sectional; cohort; and case-control studies.

The population: pregnant women aged 18 years or over presenting excess weight and a profile of dyslipidemia.

Complications investigated: the relation between physiological disorders and lipid metabolism, obesity and the lipid profile during pregnancy; dyslipidemia and gestational outcomes; lipid metabolism and transfer through the placenta and the effects of maternal dyslipidemiaon the baby.

Exclusion criteria: scientific articles that address dyslipidemia in conditions other than pregnancy and articles published in languages other than Portuguese, English or Spanish.

The theoretical framework of the selection process for systematic reviews: the initial selection of publications, using the chosen databases and proposed criteria, resulted in 2909 articles. The selection process framework for systematic reviews was then applied (Figure 1) in the following stages: identification of repeated studies; reading of keywords; reading of titles; reading of abstracts and methodological analysis and exclusion of lowimpact publications. A table was drawn up of articles that best fitted the study (Table 1).

Analysis of co-citation of key-words: after applying the process of selecting articles for systematic reviews, the key-words were then analyzed in such a way as to assess the frequency and interaction of key-words in the selected articles. Analysis of key-words thus enabled retrospective evaluation of the quality of the selection process for articles used in this systematic review. 


\section{Results and Discussion}

Relation between physiological disorders and lipid metabolism

Although most of the studies addressed concerns during pregnancy, covering various factors resulting from dietary imbalance and calorie consumption, it is worth pointing out the relation between physiological disorders and lipid metabolism during pregnancy. 2,3,5

Herrera et al. ${ }^{5}$ have shown that, during pregnancy, adipose tissue and its lipolytic activity bring about an increase in serum levels of glycerol, which is converted into glucose (in the liver) and made available for the fetus.

\section{Figure 1}

Flow-chartof activities in bibliographical selection process.

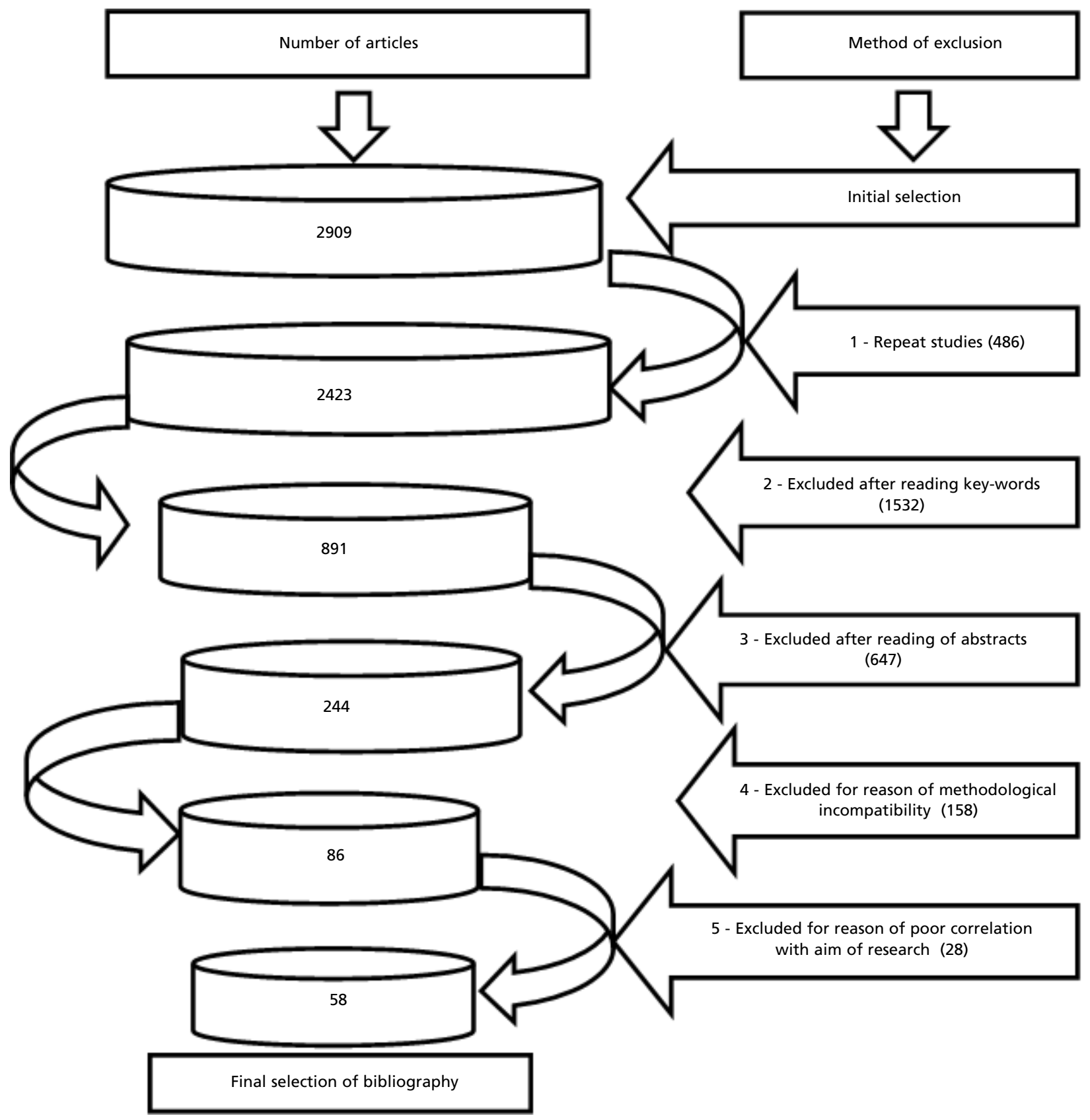


The main studies of pregnant women covered by this systematic review (2000-2015).

\begin{tabular}{lcc}
\hline Authors & Type of study & Year of publication \\
\hline Adamo et al.7 & Randomized clinical trial & 2013 \\
Oliveira et al.8 & Cross-sectional study & 2012 \\
Dempsey et al.9 & Prospective cohort study & 2004 \\
Ywaskewycz Benitez et al.10 & Case-control study & 2010 \\
Ueland et al.20 & Cross-sectional study & 2008 \\
Dann et al.28 & Prospective cohort study & 2006 \\
Aliyu et al.29 & Cross-sectional study & 2010 \\
Salihu et al.30 & Retrospective cohort study & 2009 \\
Coussons-Read et al.33 & Case-control study & 2012 \\
Kramer et al.34 & Prospective cohort study & 2009 \\
Alleman et al.35 & Retrospective cohort study & 2013 \\
Crume et al.42 & Prospective cohort study & 2015 \\
Watkins et al.43 & Case-control study & 2003 \\
Silva et al.49 & Cross-sectional study & 2014 \\
Aviram et al.51 & Systematic review & 2011 \\
Fitzsimons et al.52 & Systematic review & 2010 \\
Kristensen et al.53 & Prospective cohort study & 2005 \\
Sebire et al.54 & Cross-sectional study & 2011 \\
\hline
\end{tabular}

During pregnancy, the authors identified an increase in levels of high-density lipoprotein cholesterol (HDLC) and very low density lipoprotein cholesterol (VLDL). The concentrations obtained by measuring lipids and lipoproteins, through a comparative study with non-pregnant women, provided guidance regarding when a physiological indicator may be associated with diseases or disorders of pregnancy. 10

It is indispensable that researchers identify the various lipid conditions that are adverse in the trimesters of gestation, thereby corroborating the work of authors whose studies have confirmed the physiological factors caused by obesity in animals. Other studies have noted disorders of the central nervous system and peripheral tissue and concomitant production of ketone bodies leading to lipid oxidation. ${ }^{11,12}$

Given the evidence, it is worth noting that Herrera et al. ${ }^{5}$ stressed that gestational diabetes mellitus (GDM) and maternal fasting alter serum levels of lipids, as a result of lipolysis of adipose tissue and the production of non-esterified fatty acids (NEFAs), enabling the production of ketone bodies that are made available for the fetal plasma. ${ }^{4}$ Studies were soon developed to control adipose tissue, such as that of Ohnuki et al., 12 which highlighted the use of streptozotocin regulator Acetoacetyl-CoA Synthase (AACS) in the brains of obese rats, causing a reduction in the synthesis of cholesterol.

The increase in lipids in pregnancy is a condition characterized physiologically as normal, principally because of changes in hormones during the trimesters of gestation. However, Basaran 13 has suggested that the level of total cholesterol (TC) should not exceed $337 \mathrm{mg} / \mathrm{dL}$ nor that of triglycerides (TG) $332 \mathrm{mg} / \mathrm{dL}$, in the third trimester of pregnancy. It is worth noting the particularities of the dyslipidemic alterations in pregnancy, owing to the likelihood of the development of hyperlipidemia in the mother, given that the aforementioned studies found that pregnancy-induced hyperlipidemia contributes to an increase in certain morbidities such as GDM and pre-eclampsia.

A more recent study has compared pregnant and non-pregnant women, both of normal weight, and noted a significantly higher result for means of TG, TC, VLDL, LDLc in normal-weight pregnant women and concomitant reduction in HDLc. ${ }^{14}$ Other studies have identified a gradual increase in lipid patterns of TG, CT, VLDL and HDLc, after the $12^{\text {th }}$ week of pregnancy, especially in the second and third trimesters, in response to estrogen stimulation and resistance to insulin and pointed to the increased TG during gestation, which suggests a correlation with the risk of pre-eclampsia and preterm birth. ${ }^{15,16}$ It can be deduced that, for pregnant women of adequate weight, the increase or decrease in HDLc parameters will diverge in some scientific studies. 
However, the change in lipid patterns may suggest indicators of pathology.

Previous scientific studies including overweight and obese pregnant women have produced hypotheses and suggestions regarding a consecutive increase in dyslipidemic disorders. Studies by Mangucci et al.,17 in an attempt to identify cardiometabolic risks by comparing normal weight with overweight pregnant women, found an increase in levels of TG, CT, VLDL, LDLc for both categories, although levels of HDLc remained unaltered in normal weight pregnant women, while they were significantly low in those who were overweight.

Dyslipidemia in pregnancy and the parameters for lipid transfer from the mother to the fetus are still not fully understood. However, studies have shown that gestational dyslipidemia is influenced by the placental hormones that affect both the metabolism of glucose and that of lipids, to ensure that the fetus is supplied with nutrients essential for its development. There is, however, less flexibility in terms of metabolic adaptation in obese pregnant women compared to those of normal weight. 5,18 In obese pregnant women, therefore, both the regulation and the extent of transport of materno-fetal lipids are prone to undergo substantial physiological variations in the course of pregnancy.

It is worth noting that, even though it is clear that there are alterations in pregnancy and it is incontestable that there is a clinical and physiological disequilibrium during the gestational period, it is indispensable that the pregnant woman be accompanied and her weight controlled for the good of the health of mother and fetus alike.2,19 Research with obese pregnant women has indicated that retinolbinding protein-4 (RBP4) increases throughout pregnancy and is associated with a decline in sensitivity to insulin, thereby enabling a correlation between fasting levels of TG, LDLc, HDLc, levels of total cholesterol and resistance to insulin. 20

With all the metabolic alterations and the mother's difficulty adapting, i.e. a condition that involves necessary changes, accuracy in examinations is of fundamental importance for stable gestation, owing to the various factors that hinderweight control and performance of medically advised procedures during pregnancy. ${ }^{3}$ Pregnancy should thus be addressed as a special clinical condition, characterized by changes in the physical, psychological and social behavior of the woman. 8

Meanwhile, these correlations enable the reader to identify in each variable analyzed the consequences on maternal excess weight and the parameters used by the researchers for definition of obesity during pregnancy. Some studies have used body weight in relation to ideal weight, while others have employed the gestational body mass index (BMI). ${ }^{21-}$ 23 Authors have also shown that there is a relation between dyslipidemia and preeclampsia, especially heightened hypertriglyceridemia which has been correlated with pre-pregnancy and the body mass index of the pregnant woman. ${ }^{24} \mathrm{~A}$ scientific study by different authors reported that the increased lipolytic activity in maternal adipose tissue contributes to the development of hyperlipidemia. 5 Another study noted the rates of (maternal, fetal and neonatal) complications caused by maternal obesity, such as hyperglycemia, insulin resistance and hyperlipidemia, and concluded that obesity may pose a risk to a term pregnancy. 25

Even though various changes are to be expected during pregnancy, alterations during gestation may make it difficult to adapt to hyperlipidemic tensions and these changes may predispose the woman to other diseases, such as diabetes mellitus, chronic kidney failure and pre-eclampsia.7,26

Studies with animals may also aid scientific progress on the alterations caused by obesity. 13,14 Mertens et al.27 studied obese insulin-resistant animals with severe dyslipidemia and found a deficiency of leptin and LDL receptors in the metabolism of the animal and an increase in oxidative stress.

Although most studies address the high incidence of excessive gestational weight gain, the association between dyslipidemia, overweight and maternal outcomes are equally worrying and merit the attention of local health services, in view of their implications for the health of mother and fetus alike.

\section{Dyslipidemia and gestational outcomes}

The past decade has seen more research focused on the effects of maternal dyslipidemia. 5,9,10,24 One complication noted concerns intra-hepatic colestase, which shows that dyslipidemia may contribute to the pathogenesis of the disease and that heightened LDL and reduced HDL cholesterol may provide prior evidence of gestational intra-hepatic colestase. ${ }^{28} \mathrm{As}$ a consequence, a larger number of caesarians, the incidence of preeclampsia and the development of gestational diabetes mellitus are complications related to heightened pre-gestational BMI and excessive weight gain during pregnancy.7,29 Previous studies have already identified other complications, such as preeclampsia, chronic hypertension and diabetes. 30

Another study identified the relation existing 
between levels of lipids and the risks of preterm birth. Mudd et al.31 found low levels of lipids (TC, LDLc and HDLc) to be associated with moderately increased risks for medically indicated preterm births, and of high concentrations of TC, LDLcand TG for spontaneous preterm births.

Studies have related preterm birth to tumor necrosis factor alpha (TNF- $\alpha$ ) and likewise with lipid levels during gestation.31-34 Research has established a link between TNF- $\alpha$ and the release of lipids by adipocytes, meaning that TNF- $\alpha$ can be induced by lipolysis. 35,36 Studies have thus shown that, in mid-pregnancy, an increase in TNF- $\alpha$ and the lipid profile of pregnant women may enable the development of gestational hyperlipidemia, leading to the hypothesis of an interrelation between hyperlipidemia, TNF- $\alpha$ and preterm birth. 32,37

\section{Lipid metabolism and transfer through the placenta}

Thanks to various studies that have shown the consequences of gestational obesity, it can be stated that overweight and poorly controlled diabetes trigger physiological alterations in both the pregnant woman and the fetus. $24,38,39$

It is important to mention the function of the placenta, which plays a fundamental role in transferring lipid radicals to the fetal compartment, which may subsequently be affected by maternal diseases associated with compromised lipid homeostasis, which has an impact on fetal growth. 40 However, other variables may alter the body composition of the fetus, although these are not fully understood, especially those that relate to growing levels of resistance to maternal insulin.

Research on maternal insulin and the role it plays in the placenta has shown that insulin does not traverse the placenta, but serves to regulate nutrient sensors, which subsequently have the function of stimulating proliferation of fetal cells and growth. ${ }^{41}$ A similar process occurs with polyunsaturated fatty acids (LC-PUFA), which, in the presence of lipoprotein receptors in the placenta facilitate their acceptance, metabolizing fatty acids and spreading them to the fetus. 5

Crume et al. 42 have identified certain proteins that indirectly influence neonatal adiposity, including leptin and adiponectin, which may be stimulated when there is resistance to maternal insulin, altering the placenta transport mechanisms. At the end of pregnancy, lipid catabolism is increased and this may lead to the development of maternal hyperlipidemia and an increase in the concentration of triacylglycerols in the mother's plasma. ${ }^{5}$ It is worth noting that the metabolism of the pregnant mother is related to the production of ketone bodies, which are subsequently used by the fetus for synthesis of fatty acids, with the transfer to ketone bodies to the fetal plasma occurring by way of simple diffusion. ${ }^{5}$ For Watkins et al., ${ }^{43}$ however, the effect of fatty acids may be favored or restricted, causing serious problems for organs and fetal tissue. Physiopathological problems may thus be related to materno-fetal transport mechanisms, in the same way as the influence of the mother's lipid catabolism, which, directly or indirectly, may favor or hinder the transfer of lipids to the fetus.

\section{The effects of maternal dyslipidemia on the baby}

Gestational weight gain and obesity, in so far as they alter the intrauterine environment, are considered relevant factors and may be associated with cardiopathy and multiple anomalies in the newborns of obese women.42 However, the association between gestational obesity and neonatal characteristics has only relatively recently been studied scientifically. 44

Research in the 2000shave corroborated the importance of rigorous control of adequate exams and care in pregnancy relating to prevention and the occurrence of large for gestational age newborns in pregnant women with GMD.45-47 In another scientific study, well-controlled anthropometric measurements of children of mothers with GDM were found not to differ from those of the babies of non-diabetic mothers. 48 It is worth pointing out that pregnant women starting treatment late, having fewer consults and a higher two-hour glycemia level in the oral glucose tolerance test (OGTT 75g.) are factors frequently related to neonatal macrosomias. 49

Studies of the relation between excessive weight gain and macrosomia in newborns have concluded that there is a prevalence of $10.4 \%$ for the children of women with excessive gestational weight gain and of $2.5 \%$ for those of women with normal gestational weight gain and that this results in a larger number of caesarians and a lower Apgar score. $28,50,51$

Macrosomia, congenital diseases, neonatal death, hypoglycemia and low Apgar score in the first or fifth minute were the most frequent outcomes in this review and are also correlated with excessive weight gain during pregnancy. 27,52-55 Macrosomic babies born to obese and diabetic mothers are prone to develop glucose intolerance and childhood and 
adult obesity.7,56 Studies also suggest that obese mothers may develop early insulin resistance in the maternal uterus, which may alter fetal metabolism. ${ }^{7,29}$

Frantz et al. 57 foundin hyperlipidemia a build-up of collagen in fetal tissue creating a susceptibility to atherosclerosis in the adult life of the newborn, which may be a factor in the development of earlyonset atherosclerosis.

A study in primates has revealed that dyslipidemia may be present even in non-obese patients, when chronic consumption of a diet rich in fat may result in greater transfer of lipids to the fetus, regardless of maternal obesity and/or diabetes. Research therefore suggests that the developing fetus is highly vulnerable to excess lipids, which the increase the risk of other diseases. 58

\section{Final considerations}

Research has shown that authors are concerned

\section{References}

1. WHO (World Health Organization). WHO technical report series 894 . Obesity: preventing and managing the global epidemic. Geneva; 2000

2. Castaño IB, Sanchez PH, Perez NA, Salvador JJG, Quesada AG, García-Hernández JA, Serra-Majem L. Maternal obesity in early pregnancy and risk of adverse outcomes. PLoS One. 2013; 8: 804-10.

3. Nucci LB, Duncan BB, Mengue SS, Branchtein L, Shimidt MI, Fleck ET. Assessment of weight gain during pregnancy in general prenatal care services in Brazil. Cad Saúde Pública. 2001; 17: 1367-74.

4. Stulbach TE, Benício MHD, Andreazza R, Kono S. Determinantes do ganho ponderal excessivo durante a gestação em serviço público de pré-natal de baixo risco. Rev Bras Epidemiol. 2007; 10: 99-108.

5. Herrera E, Amusquivar E, López-Soldado I, Ortega H Maternal lipid metabolism and placental lipid transfer. Horm Res. 2006; 65: 59-64.

6. Jarvie E, Ramsey JE. Obstetric management of obesity in pregnancy. Semin Fetal Neonatal Med. 2010; 15: 83-8.

7. Adamo KB, Ferraro ZM, Goldfield G, Keely E, Stacey D, Hadjiyannakis S, Jean-Philippe S, Walker M, Barrowman NJ. The Maternal Obesity Management (MOM) Trial Protocol: a lifestyle intervention during pregnancy to minimize downstream obesity. Contemp Clin Trials. 2013; 35 87-96.

8. Oliveira MR, Dessen MA. Alterações na rede social de apoio durante a gestação e o nascimento de filhos. Estud Psicol.(Campinas). 2012; 29: 81-8.

9. Dempsey JC, Williams MA, Leisenring WM, Shy K, Luthy DA, Leisenring WM, Maternal birth weight in relation to plasma lipid concentrations in early pregnancy. Am J Obstet about excess weight and lipidemic alterations in pregnancy, showing the risks for mother and newborn alike. In terms of the negative association "obesity-pregnancy", a larger number of caesarians and cases of preeclampsia were the two most noteworthy complications for gestational outcomes.

It is clear there is a physiological demand for lipids during pregnancy. However, pathological dyslipidemia may give rise to adverse implications and complications during gestation, for the fetus and the newborn. There is no treatment for these disorders during pregnancy.

In short, the impact of care regarding maternal habits and excess weight during pregnancy is significant, given the various degrees of complications in obstetric outcomes and the influence of clinical characteristics on the newborn.
Gynecol. 2004; 190: 1359-68.

10. Ywaskewycz Benítez LR, Bonneau GA, Castillo Rascón MS, López DL, Pedrozo WR. Perfil lipídico por trimestre de gestación en una población de mujeres adultas. Rev Chil Obstet Ginecol. 2010; 75: 227-33

11. Narishima R, Yamasaki M, Hasegawa S, Fukui T. Genetic obesity affects neural ketone body utilization in the rat brain. Obesity (Silver Spring). 2009; 17: 611-15.

12. Ohnuki M, Takahashi N, Yamasaki M, Fukui T. Different localization in rat brain of the novel cytosolic ketone bodyutilizing enzyme, acetoacetyl-CoA synthetase, as compared to succinyl-CoA:3-oxoacid CoA-transferase. Biochim Biophys Acta. 2005; 1729: 147-53.

13. Basaran A. Pregnancy-induced hyperlipoproteinemia: review of the literature. Reprod Sci. 2009; 16: 431-7.

14. Thomas EA. study on alteration of serum lipid profile in gestational proteinuric hypertension. J Evol Med Dental Sci. 2015; 4: 11797-803.

15. Bartels Ä, Egan N, Broadhurst DI, Khashan AS, Joyce C, Stapleton M, O'Mullane J, O'Donoghue K. Maternal serum cholesterol levels are elevated from the 1st trimester of pregnancy: a cross-sectional study. J Obstet Gynaecol. 2012; 32: 747-52

16. Ghio A, Bertolotto A, Resi V, Volpe L, Di Cianni G. Triglyceride metabolism in pregnancy. Adv Clin Chem. 2011; 55: 133-53

17. Mangucci SB, Resende EA, Barbosa Neto O, Rodrigues Júnior V, Oliveira EM, Borges M. Obesity and cardiometabolic risk factors during pregnancy. Rev Bras Ginecol Obstet. 2014; 36: 449-55

18. Meyer BJ, Stewart FM, Brown EA, Cooney J, Nilsson S, 
Olivecrona G, Ramsay JE, Griffin BA, Caslake MJ, Freeman DJ. Maternal obesity is associated witch the formation of small dense LDL and hypoadiponectinemia in the third trimester. J Clin Endocrinol Metab. 2013; 98: 64352 .

19. Gaillard R, Durmus B, Hofman A, Mackenbach JP, Steegers EA, Jaddoe VW. Risk factors and outcomes of maternal obesity and excessive weight gain during pregnancy. Obes (Silver Spring). 2013; 21: 1046-55.

20. Ueland T, Dalsoren T, Voldner N, Godang K, Henriksen T, Bollerslev J. Retinol-binding protein-4 is not strongly associated with insulin sensitivity in normal pregnancies. Eur J Endocrinol. 2008; 159: 49-54.

21. Yu CK, Teoh TG, Robinson S. Obesity in pregnancy. BJOG 2006; 113: 1117-25.

22. Ellwood D. What can be done about maternal obesity? Aust N Z J Obstet Gynaecol. 2008; 48: 227.

23. Isaacs JD, Magann EF, Martin RW, Chauhan SP, Morrison JC. Obstetric challenges of massive obesity complicating pregnancy. J Perinatol. 1994; 14: 10-4.

24. Sharami SH, Tangestani A, Faraji R, Zahiri Z, Amiri A Role of dyslipidemia in preeclamptic overweight pregnant women. Iran J Reprod Med. 2012; 10: 105-12.

25. Joy S, Istwan N, Rhea D, Desch C, Stanziano G. The impact of maternal obesity on the incidence of adverse pregnancy outcomes in high-risk term pregnancies. Am J Perinatol. 2009; 26: 345-9.

26. Ayach W, Calderon IMP, Rudge MVC, Costa RAA. Comparação entre dois testes de rastreamento do diabetes gestacional e o resultado perinatal. Rev Bras Ginecol Obstet. 2010; 32: 222-8.

27. Mertens A, Verhamme P, Bielicki JK, Phillips MC, Quarck R, Estengel D, Ninio E, Navab M, Mackness B, Mackness M, Holvoet P. Increased low-density lipoprotein oxidation and impaired high-density lipoprotein antioxidant defense are associated with increased macrophage homing and atherosclerosis in dyslipidemic obese mice: LCAT gene transfer decreases atherosclerosis. Circulation. 2003; 107: 1640-6.

28. Dann AT, Kenyon AP, Wierzbicki AS, Seed PT, Shennan AH, Tribe RM. Plasma lipid profiles of women with intrahepatic cholestasis of pregnancy. Obstet Gynecol. 2006 107: 106-14.

29. Aliyu MH, Luke S, Wilson RE, Saidu R, Alio AP, Salihu HM, Belogolovkin V. Obesity in older mothers, gestationa weight gain, and risk estimates for preterm phenotypes. Maturitas. 2010; 66: 88-93

30. Salihu HM, Lynch O, Alio AP, Kornosky JL, Clayton HB, Mbah AK. Extreme obesity and risk of placental abruption. Hum Reprod. 2009; 24: 438-44.

31. Mudd LM, Holzman CB, Catov JM, Senagore PK, Evans RW. Maternal lipids at mid-pregnancy and the risk of preterm delivery. Acta Obstet Gynecol Scand. 2012; 91: 726-35.

32. Jelliffe-Pawlowski LL, Ryckman KK, Bedell B, O’Brodovich HM, Gould JB, Lyell DJ, Borowski KS, Shaw GM, Murray JC, Stevenson DK. Combined elevated midpregnancy tumor necrosis factor alpha and hyperlipidemia in pregnancies resulting in early preterm birth. Am J
Obstet Gynecol. 2014; 211: 141-9.

33. Coussons-Read ME, Lobel M, Carey JC, Kreither MO, D'Anna K, Argys L, Ross RG, Brandt C, Cole S. The occurrence of preterm delivery is linkedto pregnancy-specific distress and elevated inflammatory markers across gestation. Brain Behav Immun. 2012; 26: 650-9.

34. Kramer MS, Kahn SR, Rozen R, Platt RW, Chen MF, Goulet L, Séguin L, Dassa C, Lydon J, McNamara H, Dahhou M, Genest J. Vasculopathic and thrombophilic risk factors for spontaneous preterm birth. Int J Epidemiol. 2009; 38: 715-23.

35. Alleman BW, Smith AR, Byers HM, Bedell B, Ryckman KK, Murray J, Borowski KS. A proposed method to predict preterm birth using clinical data, standard maternal serum screening, and cholesterol. Am J Obstet Gynecol. 2013; 208: 472.e1-11.

36. Plomgaard P, Fischer CP, Ibfelt T, Pedersen BK, Van HG. Tumor necrosis factoralpha modulates human in vivo lipolysis. J Clin Endocrinol Metab. 2008; 93: 543-9.

37. Chen X, Xun K, Chen L, Wang Y. TNF-alpha, a potent lipid metabolism regulator. Cell Biochem Funct. 2009; 27: 40716

38. Merzouk H, Madani S, Korso N, Bouchenak M, Prost J, Belleville J. Maternal and fetal serum lipid and lipoprotein concentrations and compositions in type 1 diabetic pregnancy: Relationship with maternal glycemic control. J Lab Clin Med. 2000; 136: 441-8.

39. Abenhaim H a., Kinch R a., Morin L, Benjamin A, Usher R. Effect of prepregnancy body mass index categories on obstetrical and neonatal outcomes. Arch Gynecol Obstet. 2007; 275: 39-43.

40. Higa R, Jawerbaum A. Intrauterine effects of impaired lipid Homeostasis in pregnancy diseases. Curr med chem. 2013; 20: 2338-50.

41. Jansson T, Aye IL, Goberdhan DC. The emerging role of mTORC1 signaling in placental nutrient-sensing. Placenta. 2012; 33: 23-9

42. Crume TL, Shapiro AL, Brinton JT, Glueck DH, Martinez M, Kohn M, Harrod C, Friedman JE, Dabelea D. Maternal fuels and metabolic measures during pregnancy and neonatal body composition: the healthy start study. J Clin Endocrinol Metab. 2015; 100: 1672-80.

43. Watkins ML, Rasmussen SA, Honein M A, Botto LD, Moore CA. Maternal obesity and risk for birth defects. Pediatrics. 2003; 111: 1152-8.

44. Tennant PWG, Rankin J, Bell R. Maternal body mass index and the risk of fetal and infant death: a cohort study from the North of England. Hum Reprod. 2011; 26: 1501-11.

45. Evers IM, de Valk HW, Mol BW, ter Braak EW, Visser GH. Macrosomia despite good glycaemic control in type I diabetic pregnancy; results of a nationwide study in The Netherlands. Diabetologia. 2002; 45: 1484-9.

46. Rudge MV, Calderon IM, Ramos MD, Abbade JF, Rugolo LM. Perinatal outcome of pregnancies complicated by diabetes and by maternal daily hyperglycemia not related to diabetes. A retrospective 10- year analysis. Gynecol Obstet Invest. 2000; 50: 108-12.

47. Crncević-Orlić Z, Ruzić A, Miletić B, Petrović O, Zaputović L, Kehler T, Racki S, Kapović M. Predictive 
parameters of gestational diabetes mellitus. Coll Antropol. 2007; 31: 771-4

48. Salim R, Hasanein J, Nachum Z, Shalev E. Anthropometric parameters in infants of gestational diabetic women with strict glycemic control. Obstet Gynecol. 2004; 104: 1021-4

49. Silva JC, Bertini AM, Ribeiro TE, Carvalho LS De, Melo MM, Barreto Neto L. Fatores relacionados à presença de recém-nascidos grandes para a idade gestacional em gestantes com diabetes mellitus gestacional. Rev Bras Ginecol Obstet. 2009; 31: 5-9.

50. Kac G, Velásquez-Meléndez G. Gestational weight gain and macrosomia in a cohort of mothers and their children. $\mathrm{J}$ Pediatr. 2005; 81: 47-53.

51. Aviram A, Hod M, Yogev Y. Maternal obesity: Implications for pregnancy outcome and long-term risks-a link to maternal nutrition. Int J Gynecol Obstet. 2011; 115: 6-10.

52. Fitzsimons KJ, Modder J. Setting maternity care standards for women with obesity in pregnancy. Semin Fetal Neonatal Med. 2010; 15: 100-7.

53. Kristensen J, Vestergaard M, Wisborg K, Kesmodel U, Secher NJ. Pre-pregnancy weight and the risk of stillbirth and neonatal death. BJOG. 2005; 112: 403-8. 28
54. Sebire NJ, Jolly M, Harris JP, Wadsworth J, Joffe M, Beard RW, Regan L, Robinson S. Maternal obesity and pregnancy outcome: a study of 287213 pregnancies in London. Int J Obes Relat Metab Disord. 2001; 25: 1175-82

55. Sirimi N, Goulis DG. Obesity in pregnancy. Hormones (Athens). 2010; 9: 299-306.

56. Merzouk H, Khan NA. Implication of lipids in macrosomia of diabetic pregnancy: can n-3 polyunsaturated fatty acids exert beneficial effects? Clin Sci (Lond). 2003; 105: 51929

57. Frantz E, Menezes HS, Lange KC, Abegg MP, Correa CA, Zangalli L, Vieira JL, Zettler CG. The effect of maternal hypercholesterolemia on the placenta and fetal arteries in rabbits. Acta Cir Bras. 2012; 27: 7-12.

58. McCurdy CE, Bishop JM, Williams SM, Grayson BE, Smith MS, Friedman JE, Grove KL. Maternal high-fat diet triggers lipotoxicity in the fetal livers of nonhuman primates. J Clin Invest. 2009; 119: 323-35.

Received on november 18, 2015

Final version submitted on march 3, 2016

Approved on april 1, 2016 